\title{
SPATIOTEMPORAL VARIATION OF NDVI IN THE YELLOW RIVER SOURCE REGION FROM 1998 TO 2016
}

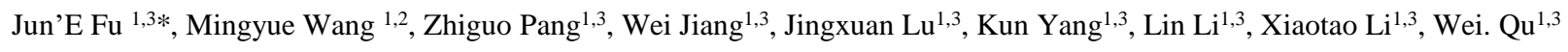 \\ ${ }^{1}$ China Institute of Water Resource and Hydropower Research, Beijing, China -(fuje,pangzg,jiangwei,lujx, yangkun, lilin , \\ lxt,quwei)@iwhr.com \\ ${ }^{2}$ Institute of Loess Plateau, Shanxi University, Taiyuan, China - sxwmyue@163.com \\ ${ }^{3}$ Research Center on Flood \& Drought Disaster Reduction of the Ministry of Water Resources, Beijing, China
}

Commission III, ICWG III/IVc

KEY WORDS: NDVI, spatiotemporal variation, trend analysis, land use, climatic elements, the Yellow River source region

\begin{abstract}
:
Quantification of vegetation change and its coupling relationship with climate change has become the central topic in current global change researches. The Normalized Difference Vegetation Index (NDVI) time series data and meteorological data from 1998 to 2016 were collected to investigate the temporal and spatial variations of NDVI in growing season in the Yellow River source region and its response to climate change, based on the trend analysis, Mann-Kendall test and correlation analysis. The results indicated that: (1) In the past 19 years, the average NDVI in the region showed a slow increase, with a growth rate of 0.002/a and a catastrophe point in 2005, and the area with an upward trend accounted for $71.4 \%$ of the total area. (2)The climate of the area had been becoming warm and moist since the recent 19 years, both precipitation and temperature in growing season showed an upward trend. The partial correlation analysis showed that NDVI was positively correlated with precipitation and temperature, significantly relevant area accounting for $31.01 \%$ and $56.40 \%$ of the total area individually. The sensitivity of NDVI to temperature was higher than that of precipitation. According to residual analysis over the 19 years, human activities had negative effects on NDVI accounting $53.58 \%$ of the study area, and the implementation of a series of ecological protection engineering measures was the main cause leading to an increasing trend of NDVI after 2005.
\end{abstract}

\section{INTRODUCTION}

The global environmental change marked by "global warming" and its possible serious impacts on the ecosystems have attracted great attention of scientists around the world (Walther, 2002). Studies show that the period from 1983 to 2012 was the warmest 30 years in the Northern Hemisphere over the past 800 years(IPCC,2013). As the main body of terrestrial ecosystem, vegetation is a sensitive indicator of climate change(Wang, 2003). Therefore, in the context of global climate change, it is of great significance to master the spatiotemporal variation of vegetation cover to regulate ecological processes and ensure ecological security.

NDVI can be used to measure the improvement and degradation of vegetation cover. Its time series can intuitively reflect the vegetation growth and coverage status(Zhang, 2014), and has been widely used in global and regional vegetation change research. The global interannual changes in vegetation activities were monitored using NDVI and its relationships to temperature and precipitation(Kawabata,2001; Myeni,1997). The vegetation NDVI changes in China from 1982 to 2012 was a slowly increasing trend with obvious regional characteristics, and the increasing trend slowed down after 1997(Liu, 2015). The study on vegetation cover in China from 1982 to 1999 using GIMMS NDVI data showed that $86.2 \%$ of China's area was an increasing trend, and the changes in vegetation NDVI were significantly affected by climate fluctuations and had obvious regional differences (Piao, 2001). G.C.[10] analysed vegetation coverage in China from 2000 to 2015 showed that the area with increased vegetation coverage accounted for $83.34 \%$ in China. Many scholars (Xu,2007; Chen,2010; Zhang,2018) have also research much about the vegetation changes in more regions of China. These studies show that vegetation coverage in different regions was increasing, and ecosystem of Qinghai-Tibet Plateau is very fragile, more sensitive and rapid response to climate change.

The Yellow River source region, located in the northeast of the Qinghai-Tibet Plateau, is an important part of the terrestrial ecosystem. It is also a water conservation area and a key protected area in the Yellow River basin. With the ecological protection of the Yellow River Basin becoming a major national strategy, it is of great significance to dynamically monitor the spatiotemporal variation of surface vegetation cover. In the past 10 years, the temperature and precipitation increased [17-19] in the Yellow River source region, the vegetation coverage tended to improve(Jiang, 2015), and the landscape ecological changed significantly (Pan,2005). The warm climate and humidification may be the main reason for the improvement of vegetation growth in the Yellow River source region(Xu,2012). The increase in vegetation coverage was mainly due to temperature rise and the implementation of ecological protection projects in the Yellow River source region(Zhang, 2019). But most scholars pay more attention on the intra- and inter-annual change of vegetation coverage in the Yellow River source region and the less to vegetation change of different land use types. The change of land use are a direct result of regional

\footnotetext{
* Corresponding author
} 
environmental changes and human activities. Therefore, based on the NDVI data and meteorological data from 1998 to 2016, this paper analysed the spatiotemporal variation of NDVI during growing season (May-September) in the Yellow River source region and its response mechanisms of different land use types. It provides scientific basis for countermeasures of vegetation protection in alpine regions under the background of global warming.

\section{MATERIALS AND METHODS}

\section{Study area}

The Yellow River source region, presented in Figure 1 (32 ${ }^{\circ} 09$ $36^{\circ} 34^{\circ} \mathrm{N}, 95^{\circ} 54^{\circ}-103{ }^{\circ} 24 \mathrm{E}$ ), locates in the northeast of the Qinghai-Tibet Plateau and covers an area of $131400 \mathrm{~km}^{2}(\mathrm{Hu}$, 2014), accounting for $16.2 \%$ of the Yellow River basin area. The study area covers from the source of the Yellow River to Longyangxia reservoir, mainly involving 20 counties in Qinghai, Gansu and Sichuan provinces. Its overall terrain shows the eastlow and west-high feature, with an elevation between 2410 to $6253 \mathrm{~m}$. The climate type is inland alpine climate, cold and dry and has sufficient sunshine. The temperature and precipitation decrease from southeast to northwest, with an average annual temperature of $1.45{ }^{\circ} \mathrm{C}$ and average annual precipitation of $367.03 \mathrm{~mm}$. Its vegetation types mainly include alpine grasslands, alpine meadows and alpine shrubs. Grassland was the main type of land cover, accounting for $74.55 \%$, followed by unused land, accounting for $15.37 \%$. There are a large area of glaciers and permafrost with a great number of lakes and rivers, a large number of marsh wetlands are developed, which provides more than $40 \%$ of the runoff in the Yellow River basin ( $\mathrm{Li}, 2012)$. This region is an important water conservation area and water supply area of the Yellow River, known as the "water tower" of the Yellow River basin.

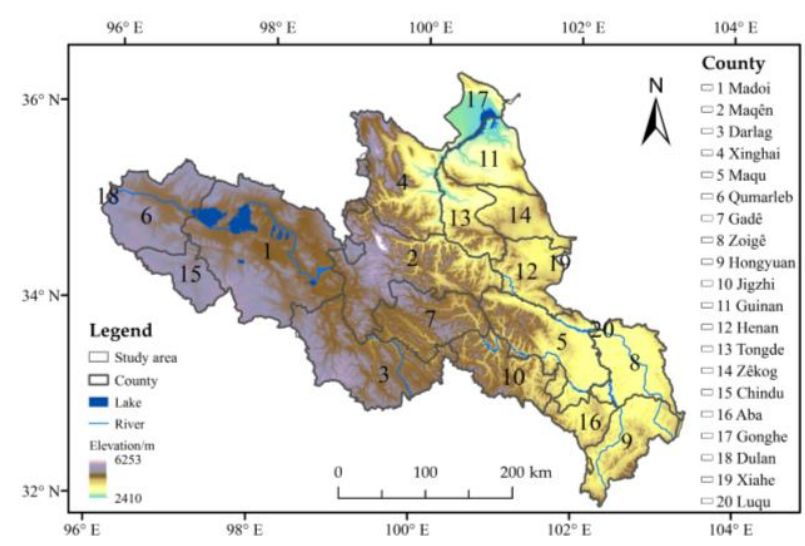

Figure 1. The study area

\section{Data Collection}

In this study, we used NDVI data, meteorological data and landuse data to monitor the temporal variations and trends of NDVI of study area from 1998 to 2016. The NDVI satellite dataset was obtained from the Resources and Environment Science Data Center (RESDC) of the Chinese Academy of Sciences $(\mathrm{Xu}, 2018)$. We used monthly composite data at a $1 \mathrm{~km}$ resolution. Data preprocessing done at the RESDC includes atmospheric correction, radiation correction, geometric correction and maximum value composites (MVC) by SPOT / VEGETATION and MODIS. The data has been widely used in many areas of China. In addition to that, we removed noisy pixels characterized by exceptionally high or low NDVI values relatively to their neighbourhood. The monthly average value of NDVI from May to September were calculated to obtain the annual value during the growing season. The daily meteorological gridded precipitation (Pre) and temperature (TM) time-series were provided by the National Climate Center, with spatial resolution of $0.25^{\circ}$ (Xu, 2009; Gao, 2008). The daily values were summed from May to September to get the annual values in growing season. The land-use data in 2015 were also obtained from the RESDC, with a spatial resolution of $100 \mathrm{~m}$. We classified the land into 6 categories: cropland, forest land, grassland, water body, built-up land and unused land.

\section{Method}

The linear regression trend model (Stow, 2007) was used to simulate the trend of each raster pixel and analyse the spatial characteristics of NDVI change. In the method, time $t$ was set as the independent variable with NDVI value of each pixel for dependent variable, and the slope of linear regression was the very index quantifying the trend of vegetation variations in the study period. The slope value meant the average annual increase (or decrease) of NDVI from 1998 to 2016. The calculation of the slope is as follows:

$$
e_{\text {slope }}=\frac{n \times \sum_{i=1}^{n} i \times N D V I_{i}-\sum_{i=1}^{n} i \times \sum_{i=1}^{n} N D V I_{i}}{n \times \sum_{i=1}^{n} i^{2}-\left(\sum_{i=1}^{n} i\right)^{2}}
$$

where $\quad e_{\text {slope }}=$ the slope of the linear regression of NDVI

$i=$ year serial number

$n=$ cumulative number of monitoring year

$N D V I_{i}=$ the mean value of NDVI in the $\mathrm{i}$-th year

Mann-Kendall test analysis (Snyers, 1990; Wei, 1999) was applied to explore the trends of NDVI time series. In the method, an order sequence for $\mathrm{n}$ samples was constructed and then $U F_{k}$ and $U_{k}$ curves and significant horizontal lines were drawn. If the $U F_{k}$ is greater than 0 , it means that the sequence shows an upward trend, and less than 0 indicates a decline. When the threshold exceeds \pm 1.96 , it indicats that the trend is significant. The region beyond the confidence level is the mutation region of the sequence. If there are intersection points between $\mathrm{UF}_{\mathrm{k}}$ and $\mathrm{UB}_{\mathrm{k}}$ curves with the confidence interval, have, the time corresponding to the intersection point is the time point of possible sudden start.

We used partial correlation analysis to identify the relationship between climatic factors (Pre and TM) and average NDVI of growing season. Partial correlation analysis is that when the two variables associate with the third variable at the same time, it will exclude the impact of the third one and only analyze the correlation of the other two variables (Liu, 2005). The partial correlation coefficients passed the significant level with t test. In addition, we applied the residual analysis method to analyse the impact of human activities on NDVI changes (Zhang, 2018).

\section{RESULTS AND ANALYSIS}

\section{Temporal and spatial variation of vegetation NDVI}

Figure 2a illustrated the spatial distribution of vegetation NDVI in growing season in the Yellow River source region from 1998 to 2016. NDVI distribution has a large regional difference, and NDVI in the southeast is higher than that in the northeast. The 
annual average NDVI of the study area is 0.486 . The maximum NDVI was 0.76, located in the Zoige Grassland Wetland and maximum NDVI was lower than 0.1 , located in the west of the study area, mainly covering with ice and snow.

The NDVI in the study area increased slowly over the past 19 years, with a linear trend of 0.002 /a. The overall environmental condition had been improved in different degree, but vegetation degradation or deterioration occurred in some areas (figure 2b).The area where NDVI increased accounted for $71.40 \%$ of the total area from 1998 to 2016, and the rapidly increasing area accounted for $33.12 \%$, mainly distributed in the southeast. $19.41 \%$ of the areas did not change significantly, mainly in Madoi, Gade and Huangshatou in Guinan. The reduced area accounted for 9.19\%, mainly in Mnqen and Gonghe.

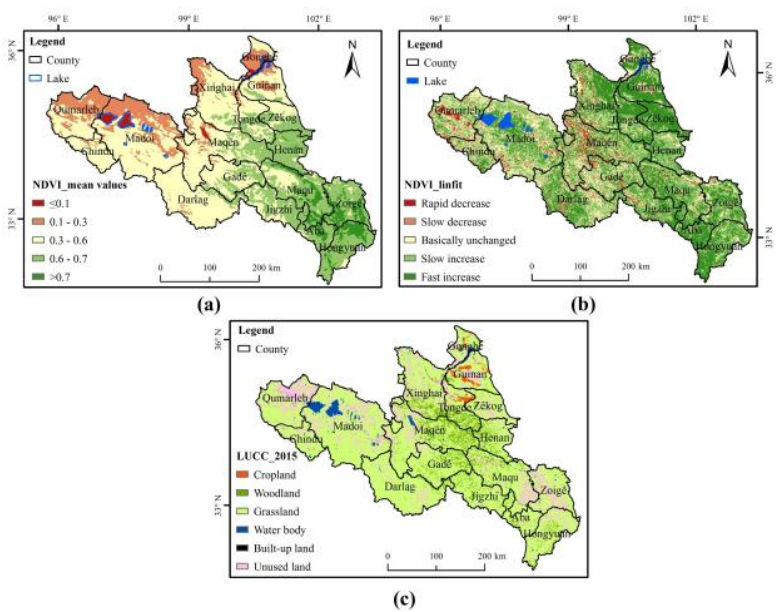

Figure 2. (a)Spatial distribution of the mean NDVI in region from 1998 to 2016; (b)Spatial distribution of the change trend for NDVI in region from 1998 to 2016; (c) Land use types in region in 2015.

The NDVI variations in growing season of 6 land use types were analysed from 1998 to 2016 and the $\mathrm{UF}_{\mathrm{k}}$ and $\mathrm{UB}_{\mathrm{k}}$ curves were drawn (Figure 3).

The proportion of grassland in the study area was the highest, so the trend consistency of grassland NDVI and the whole region was also the highest. Except the water body, NDVI of other land cover types in the region showed an upward trend. Among the six land use types, the cropland NDVI increased obviously, with the linear trend of 0.006/a, and the NDVI of woodland and grassland increased slowly, with the linear trend of 0.002/a. NDVI of Built-up land and unused land showed a slight increase trend with the linear trend of $0.001 / \mathrm{a}$.

As can be seen from Figure $3 a$, the $U F_{k}$ and $U B_{k}$ curves had an intersection in 2005. Before 2005, NDVI value was lower than the multi-year NDVI average, and after 2005 it fluctuated around the average value, indicating that the vegetation coverage in the region was increased greatly since 2005. As we known, the "Master Plan for Ecological Protection and Construction of the Three-River-Source Nature Reserve in Qinghai" was approved and launched in 2005 (The State Council, 2005), and then a series of engineering measures had been implemented. Therefore, with the implementation of those ecological protection measures, the vegetation in the study area had been restored a certain extent.
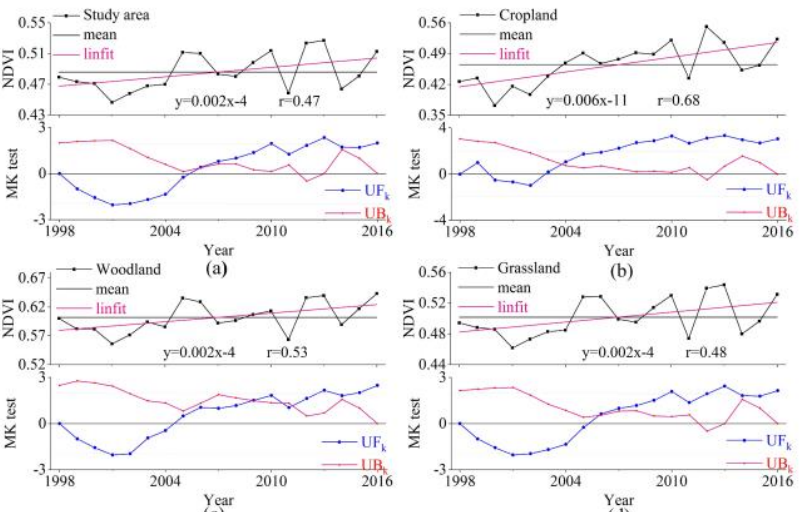

Year

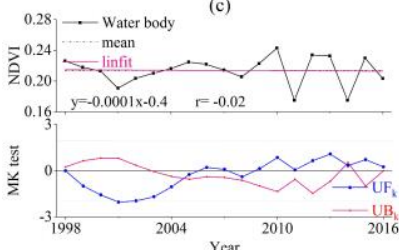

0.51 - Built-up land

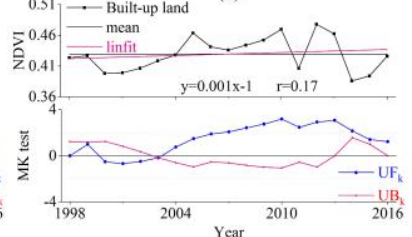

(e)

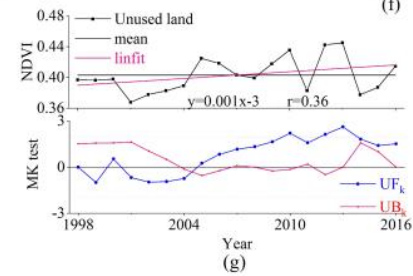

Figure 3. Temporal change of the NDVI in Different land use types: (a) the Yellow River source region; (b) cropland; (c) woodland; (d) grassland; (e) water body; (f) built-up land; (g) unused land.

\section{Impact of Meteorological Elements on Vegetation NDVI}
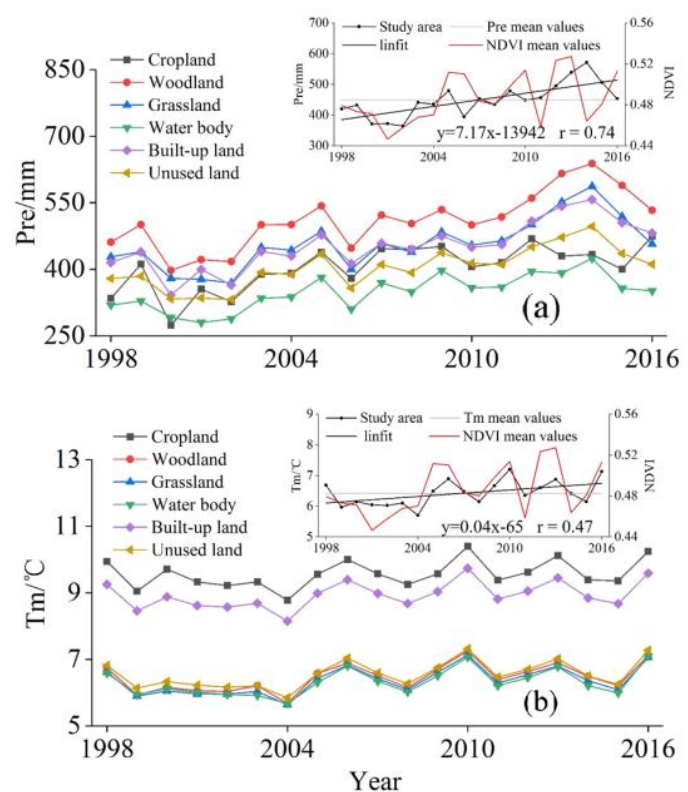

Figure 4. Temporal change of the climate elements in region from 1998 to 2016: (a) precipitation; (b) temperature. 

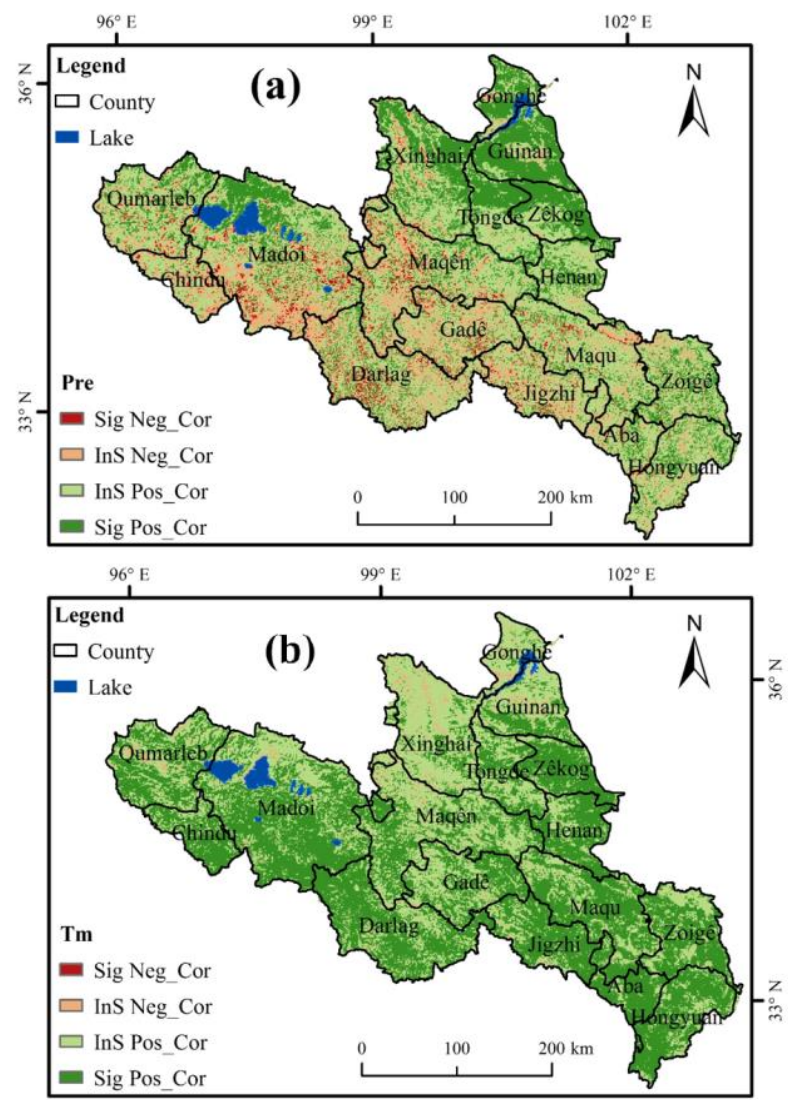

Figure 5. Spatial distribution of the correlation analysis between NDVI and climatic factor: (a) precipitation; (b) temperature.

Vegetation changes were the result of climate change and human activities( $\mathrm{Du}, 2015)$. Precipitation and temperature are the main climatic factors affecting vegetation NDVI change. As shown in Figure 4, the precipitation during the growing season in the region showed an upward trend with a linear value 7.17/a and an average value of $449.52 \mathrm{~mm}$. The average temperature was rising, with a linear value $0.04 / \mathrm{a}$ and an average value of $6.42^{\circ} \mathrm{C}$. As shown in Figure 5, NDVI in the whole region had positive correlation with precipitation and temperature, and the consistency between NDVI and temperature was better than the consistency with precipitation. That meant the sensitivity of NDVI to temperature is higher than that of precipitation, which shows that temperature has a greater impact on vegetation. In terms of six different types of land use, cropland NDVI has the best correlation with precipitation, followed by woodland.

\section{Impact of human activities on vegetation NDVI}

The residual analysis method was used to simulate the relationship between NDVI and 2 climatic factors of each pixel. The residual changes of NDVI prediction and observation reflected the influence of human activities on NDVI actual changes. Positive residuals indicate that the human impact on vegetation is positive, while the negative residuals indicate that the human impact is negative (Liu, 2015). Figure 6a showed the spatial distribution of residuals in the study area from 1998 to 2016. It can be seen that about $53.58 \%$ of the study area was negative, mainly including the central and western regions in the source region, and Maqen accounted for the highest proportion. In addition, $46.42 \%$ of the area was positive, mainly in Hongyuan, Aba, Zoige, Maqu and Zeku.
The results of the residuals of different land use types showed that the residuals of cropland and built-up land fluctuated greatly, and the human activities impact on these two types were more obvious. Studies (Xiao, 2020) showed that Maddo's builtup land expanded rapidly after 2010. The ecological security evaluation on Maqen's land in 2013 (Feng, 2016) showed that, the vegetation in the western area of Maqen were more sensitive and risk-based. The positive NDVI residuals of vegetation were from 2004 to 2006 and from 2012 to 2013. To a certain extent, after the establishment of the Three-River-Source Nature Reserve (2000), the Implementation of the ecological protection construction project (2005) had already achieved initial results. Thus, anthropogenic factors were the main causes leading to an increasing trend of NDVI after 2005. However, its influencing mechanism remains to be further investigated.

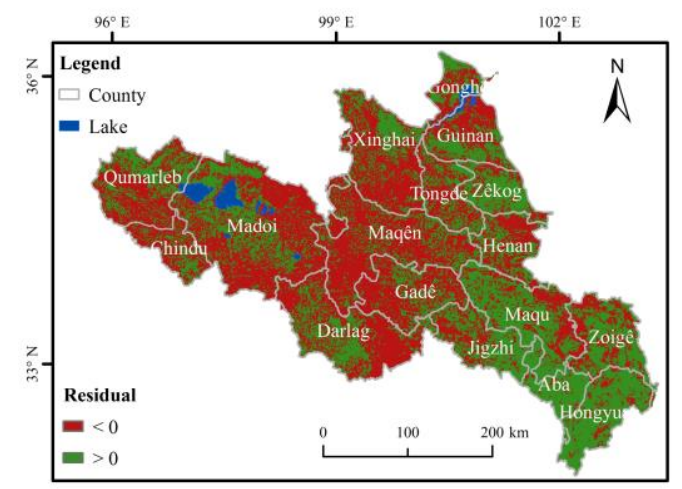

(a)
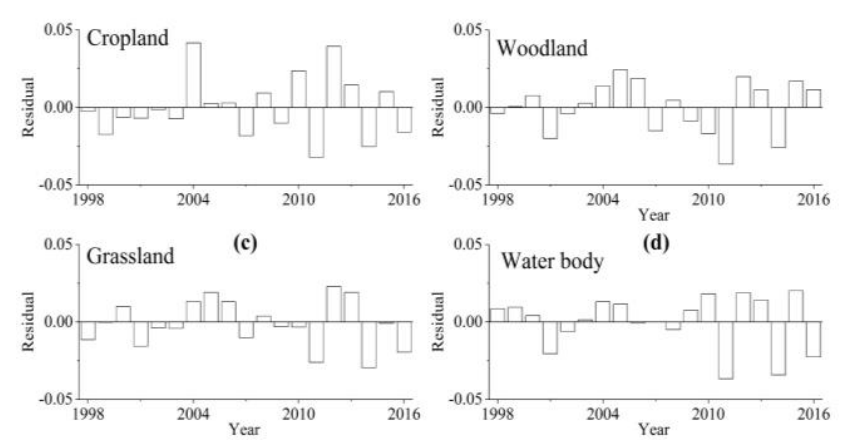

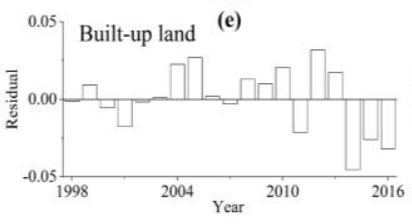

(g)

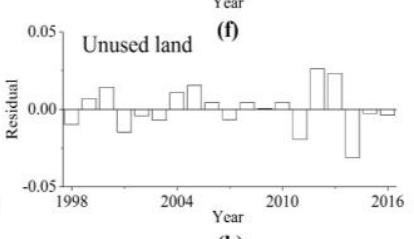

(h)
Figure 6. Residual analysis for NDVI :(a)Spatial distribution of the Yellow River source region; (b) Temporal series of the Yellow River source region. (c) Temporal series of the cropland; (d) Temporal series of the woodland; (e) Temporal series of the grassland; (f) Temporal series of the water body; (g) Temporal series of the built-up land; (h) Temporal series of the unused land.

\section{CONCLUSIONS}

Based on the NDVI and climate data in growing season from 1998 to 2016, this study used Mann-Kendall test and residual analysis to analyse the spatial and temporal characteristics of NDVI and its impact factors in the source region. The results shows that: 
(1) The average NDVI in growing season from 1998 to 2016 was 0.486 , which decreased from northwest to southeast, with obvious regional differences. The NDVI values were between 0.3 with 0.6 , accounting for $50.77 \%$. NDVI in the study area showed a trend of "increasing overall and decreasing locally", of which $71.40 \%$ showed an increasing trend. For different land use types, NDVI value of forestland was the highest, and the NDVI trend coincides best with the grassland NDVI trend.

(2) The NDVI variations in the study area were the result of the combined effect of meteorological elements and human activities. During the 1998 to 2016, both precipitation and temperature showed an increasing trend. These might be the main reasons for the warm and humid climate in the study area in recent years, and the warm and humid trend was helpful to the improvement of vegetation.

(3) The results of partial correlation analysis indicated that the correlation between temperature and NDVI is greater than the correlation between precipitation and NDVI. This meant the sensitivity of vegetation and temperature was higher than that of precipitation. Farmland NDVI had the best correlation with precipitation, while grassland NDVI had the best correlation with temperature.

(4) The results of the residual analysis showed that human activities had a positive impact on $46.42 \%$ of the whole study area, indicating that human activities and other factors had a certain positive impact on the ecological environment. However, $53.58 \%$ of the area was still negatively affected by human activities, which proved that the trend of grassland degradation in the source region had not been effectively curbed. The cultivated land and construction land were affected more obviously by human activities.

\section{ACKNOWLEDGEMENTS}

This work was supported by the National Key Point Research and Invention Program of the Thirteenth Five Year Plan (2017YFA0605003).

\section{REFERENCES}

Chen, H.L., Liu, Y.J., Du, Z.X., Zhou C.H., 2010: Spatiotemporal variations of vegetation cover in Huang-HuaiHai area based on remote sensing data. Chinese Journal of Ecology, 29(5),991-999.

Chen, H., Liu, X., Ding, C., Huang, F., 2018: Phenology-Based Residual Trend Analysis of MODIS-NDVI Time Series for Assessing Human-Induced Land Degradation. Sensors, 18.

Du, J.Z., Wang, G.X., Li, Y.S., 2015: Rate and causes of degradation of alpine grassland in the source regions of the Yangtze and Yellow Rivers during the last 45 years. Acta Prataculturae Sinica, 24, 5-15.

Feng, Y.J., 2016: Changes of Vegetation Coverage from 2005 to 2015 of Maqin County in Three-river Headwater Region. Journal of Dalian Minzu University, 18(5), 450-456.

Gao, X.; Shi, Y.; Song, R.; Giorgi, R.; Wang, Y.; Zhang, D., 2008: Reduction of Future Monsoon Precipitation over China: Comparison between a High Resolution RCM Simulation and the Driving GCM. Meteorology and atmospheric physics, 100:73-86.

Hu, G.Y., Jin H.J., Dong, Z.B., Yan, C.Z., Lu, J.F., 2014: Research of land-use and land-cover change ( LUCC) in the source regions of the Yellow River. Journal of Glaciology and Geocryology, 36(3), 573-581.

IPCC, 2013: The Physical Science Basis. Contribution of Working Group I to the Fifth Assessment Report of the Intergovernmental Panel on Climate Change. Intergovernmental Panel on Climate Change 1535.

Jiang, C., Zhang, L.B., 2015: Climate Change and Its Impact on the Eco-Environment of the Three-Rivers Headwater Region on the Tibetan Plateau, China. International Journal of Environmental Research and Public Health, 12(10),1205712081.doi: 10.3390/ijerph121012057.

Kawabata, A.; Ichii K.; Yamaguchi Y. , 2001: Global monitoring of inter-annual changes in vegetation activities using NDVI and its relationships to temperature and precipitation. International Journal of Remote Sensing, 22,1377-1382.

Li, L., Shen, H.Y., Dai, S., Xiao, J.S., Shi, X.H., 2012: Response of runoff to climate change and its future tendency in the source region of Yellow River. Journal of Geographical Sciences, 66(9),1261-1269. doi: 10.11821/xb201109011.

Li, X.J. 2019: Study on the Spatial-Temporal Distribution Characteristics of Extreme Precipitation in Recent 5 Years in Mainland China and its Relationship with Secondary Disasters Based. Lanzhou University.

Liu, S.Z., 2005: Theory, method, application and software calculation of mathematical statistics. Hua China University of science and Technology Press, Wuhan.

Liu, X.F., Zhu, X.F., Pan, Y.Z., Li, Y.Z., Zhao A.Z., 2015: Spatiotemporal changes in vegetation coverage in China during 1982-2012. Acta Ecologica Sinica, 35(16), 5331-5342.

Myneni, R.B., Keeling, C.D., 1997: Increased plant growth in the northern high latitudes from 1981 to 1991. Nature, 386, 698-702.

Snyers, R., 1990: On the statistical analysis of series of observations. Technical Note, WMO, Geneva.

Stow, D., Petersen, A., Hope, A., 2003: Variability of the seasonally integrated normalized difference vegetation index across the north slope of Alaska in the 1990s. International Journal of Remote Sensing, 24(5), 1111-1117.

The State Council, 2005: Overall Planning of Ecology Protection and Construction in the Nature Reserve of Three Rivers' Source Region in Qinghai Province, 1-54.

Pan, J.H.; Liu, J.L., 2005: Land Use Change and Its Impact in the Eco-environment on the Yellow River Source Region During the Past 15 Years. Journal of arid land resources and environment, 19(4),69-74. 
Piao, S.L., Fang, J.Y., 2001: Dynamic vegetation cover change over the last 18 years in China. Quaternary Sciences, 21(4),294-302.

Walther, G. R. , Post, E. , Convey, P. , Menzel, A. , Parmesan, C. , \& Beebee, T. J. C. , et al., 2002: Ecological responses to recent climate change. Nature, 416(6879), 389-395.

Wang, L.X.; Yang, Y.L.; He, Y.H., 2003: Discussion of research methods on relationship between climate change and plant. Chinese Journal of Ecology, 22(1),43-48.

Wei F.Y., 1999: Modern Technology of Statistics, Diagnosis and Forecast for Climate. China Meteorological Press, Beijing.

Xiao, J.S., Qiao, B., Chen, G.Q., Shi, F.F., Cao, X.Y., Zhu, C.X., 2020: Land use change and evolution of ecosystem service value in Maduo County of source region of the Yellow River. Acta Ecologica Sinica, 40(2):510-521.

Xu, H.J., Yang, T.B., Zeng, B., 2012: Spatial-temporal variation of growing-season NDVI and its responses to climate change over the source region of the Yellow River. Ecology and Environmental Sciences, 21(7), 1205-1210. doi: 10.16258/j.cnki.1674-5906.2012.07.001.

Xu, W.X; Liu, X.D., 2007: Response of Vegetation in the Qinghai-Tibet Plateau to Global Warming. Chinese Geographical Science,17(2),151-159. doi: 10.1007/s11769007-0151-5.

Xu, X.L., 2018: China Monthly Vegetation Index (NDVI) spatial distribution data set, Data Registration and Publishing System of the Resource and Environmental Data Cloud Platform Centre of the Chinese Academy of Sciences. doi: $10.12078 / 2018060602$.

Xu, Y., Gao, X.J., Shen, Y., Xu, C.H.; Shi, Y., GIORGI, F., 2009: A Daily Temperature Dataset over China and Its Application in Validating a RCM Simulation. Advances in Atmospheric Sciences, 26, 763-772.

Zhang, C., Li, Q., Li, Z.F., 2014: Influence of Human Activities on Variation of Vegetation Cover in the Three-River Source region. China Population, Resources and Environment.

Zhang, L., Ding M.J., Zhang, H.M., Wen, C., 2018: Spatiotemporal Variation of the Vegetation Coverage in Yangtze River Basin during 1982-2015. Journal of Natural Resources, 33(12), 2084-209. DOI: 10.31497/zrzyxb.20171056.

Zhang, X.L., Huang, L.M., Quan, Q., Zhang, L., Shen, B., Mo, S.H. 2019: Relationship of vegetation cover chang with climate factors in source region of the Yellow River based on ITPCAS forcing data. Journal of Northwest A\&F University,47(9),55-68.

Zhang, Z.N., Qi, Y.J., Zhang, Y., 2018: Study of Human Influence on Chifeng Vegetation Change Based on Residual Trend Method. Ecological Economy, 34(9), 206-211. 